http://jmscr.igmpublication.org/home/ ISSN (e)-2347-176x ISSN (p) 2455-0450

crossref DOI: https://dx.doi.org/10.18535/jmscr/v7i11.38

Journal Of Medical Science And Clinical Research

\title{
A Study of Association of Subclinical Hypothyroidism with Ischemic Heart Disease
}

Authors

\section{J.Ilankumaran ${ }^{1}$, Saritha K. Narayanan ${ }^{2 *}$, M. Ramakrishna Rao ${ }^{3}$}

${ }^{1}$ Post graduate, Department of General Medicine, Rajah Muthaiah Medical College, Chidambaram Tamilnadu

${ }^{2}$ Associate Professor, Department of General Medicine, Rajah Muthaiah Medical College, Chidambaram, Tamilnadu

${ }^{3}$ Professor, General Medicine, Rajah Muthaiah Medical College, Chidambaram, Tamilnadu *Corresponding Author

\section{Dr Saritha.K.Narayanan}

\begin{abstract}
Aims and Objectives: To study the association of Ischemic Heart Disease in Subclinical Hypothyroidism in women above 50 years of age.

Methods

Case Selection: Women more than 50 years of age attending the Medical outpatient clinic at RAJA MUTHAIAH MEDICAL COLLEGE and HOSPITAL, Chidambaram are screened for the presence of subclinical hypothyroidism based on the presence of biochemical evidence of thyroid hormone deficiency in patients who have few or no apparent clinical features of hypothyroidism. Among the patients screened, 100 patients with subclinical hypothyroidism are included in the study.

Results: 320 women above the age of 50 years who visited the Medical outpatient clinic during the study period were studied.100 women were found to have the criteria set for the definition of subclinical hypothyroidism, which meant a rate of $31.25 \%$, and a total of 23 patients among those had Ischemic heart Disease.

Conclusion: Patients with subclinical hypothyroidism are at risk of developing Ischemic Heart Disease.
\end{abstract}

\section{Introduction}

By definition, Subclinical hypothyroidism (SH) refers to biochemical evidence of thyroid hormone deficiency in patients who have few or no apparent clinical features of hypothyroidism.

Subclinical hypothyroidism is a common disorder with prevalence ranging from $1-10 \%$ of the, mostly adult, population ${ }^{1-5}$, with the highest rate approaching $26 \%$ in elderly women ${ }^{6}$.

Clinical manifestations of subclinical hypothyroidism include abnormal lipid metabolism, cardiac dysfunction, and neurological and mental dysfunction. Several cross-sectional studies have suggested that it confers an elevated risk of atherosclerosis and coronary heart disease with however only a few longitudinal studies have been conducted till now. The relationship between subclinical hypothyroidism and cardiovascular disease is therefore controversial, and possible outcomes of the condition remain unclear. Importantly, several previous studies suggesting that thyroid autoimmunity is a risk factor for 
coronary heart disease remain surrounded by controversy.

The present study has been performed to estimate the association between Ischemic Heart Disease in subclinical hypothyroidism women above the age of 50 years attending Medical outpatient clinic at RAJA MUTHAIAH MEDICAL COLLEGE and HOSPITAL, Chidambaram.

\section{Aims and Objectives}

1. To study the prevalence of subclinical hypothyroidism in women above the age of 50 years.

2. To study the association between Ischemic Heart Disease and subclinical hypothyroidism in those women.

\section{Inclusion Criteria}

All women aged above 50 years of age attending OPD or admitted to RMMCH with subclinical hypothyroidism.

\section{Exclusion Criteria}

Those with

- Known thyroid disease

- History of neck irradiation

- Chronic renal failure

- Severe illness (such as infection, recent myocardial infarction, heart failure, or recent intensive care admission)

\section{Materials and Methods}

\section{Case Selection}

Women more than 50 years of age attending the Medical outpatient clinic at RAJA MUTHAIAH MEDICAL COLLEGE and HOSPITAL, Chidambaram are screened for the presence of subclinical hypothyroidism based on the following parameters-Normal Free T3, Free T4 and elevated TSH level above $5.5 \mathrm{micro} \mathrm{IU} / \mathrm{ml}$.Among the patients screened, 100 patients with subclinical hypothyroidism are included in the study.

\section{Measurements}

Thyroid function test - Free T4, free T3, and TSH levels were measured. Thyroid function test is done using the electrochemiluminescence method. The normal range for TSH is $0.30-5.50 \mu \mathrm{IU} / \mathrm{ml}$, for free T4 the normal range is $0.70-1.80 \mathrm{ng} / \mathrm{dL}$, and for free T3 it is $1.70-4.20 \mathrm{pg} / \mathrm{ml}$.

\section{Clinical Assessments}

Participants with subclinical hypothyroidism were examined for the presence of goitre and symptoms of hypothyroidism.

\section{Analytical methods}

The following data were collected from the entire study group:

- Age

- Ischemic heart disease (defined as angina or myocardial infarction by self-report or by analysis of a standard 12 lead ECG)

Comparison was done between patients with subclinical hypothyroidism with the above mentioned evidence of IHD and without evidence of IHD.

\section{Statistical Analysis}

The data collected were entered into Microsoft excel spread sheet 2017 and the data was imported into Statistical analysis was done using the Statistical Package for Social Sciences (SPSS) version 21 for further analysis. Descriptive statistical methods were used as appropriate. Mean \pm SD were used to express the distribution of the variable for quantitative data. Categorical data were expressed in terms of frequencies and percentages. In appropriate places the data have also been expressed using diagrams like bar chart and pie charts.

\section{Results and Analysis}

320 women above the age of 50 years who visited the Medical outpatient clinic during the study period were screened. Out of the patients who have satisfied the criteria set for the definition of subclinical hypothyroidism, 100 patients were randomly selected for the study. A total of 23 patients had Ischemic heart Disease which has been represented in fig 1 . 


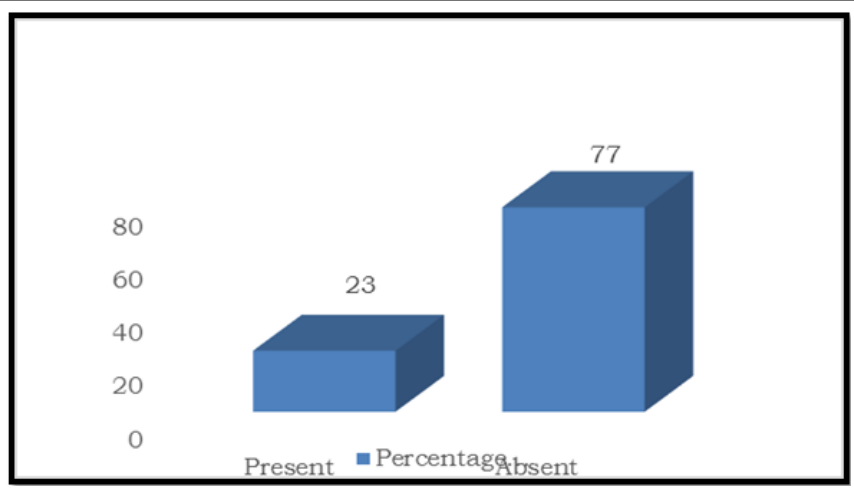

Fig.1

\section{Discussion}

Subclinical hypothyroidism is common in elderly women. A prevalence of $11-26 \%$ had been reported in previous studies ${ }^{7}$, while our study showed that $31.25 \%$ of the elderly women above the age of 50 years attending the outpatient clinic had subclinical hypothyroidism. This higher prevalence in our population could be due to environmental or genetic factors, which should be verified in further studies.

Surveys that stratified TSH levels indicate a predominance of $\mathrm{TSH}<10 \mu \mathrm{IU} / \mathrm{ml}$, which accounts for $55-85 \%$ of cases ${ }^{8}$. Almost $47 \%$ of our patients with subclinical hypothyroidism had $\mathrm{TSH}<10 \mu \mathrm{IU} / \mathrm{ml}$. Studies that have reported thyroid antibody test on subjects with elevated TSH demonstrated seropositivity rates from 20 $78 \%{ }^{9,10}$.

Several studies have suggested that mild symptoms of hypothyroidism are more prevalent in patients with subclinical hypothyroidism than in age-matched controls; fatigability and weight gain were the most frequent, but not all studies have found this to be true. Twenty-nine percent of our patients with subclinical hypothyroidism had symptoms, fatigability being the most common.

There have been three published randomized prospective placebo-controlled trials on the therapy of symptoms in patients with subclinical hypothyroidism. Two trials reported significant improvement in the symptoms of hypothyroidism, whereas the third found no benefit of therapy. The benefit of therapy was related to TSH level, being more in those whose mean serum TSH was 12.7 $\mathrm{mU} / \mathrm{l}$ at base line. In women with subclinical hypothyroidism and ovulatory dysfunction, thyroxine therapy may restore fertility ${ }^{11}$.

Case control and cross-sectional studies on the association between subclinical hypothyroidism and cardiovascular diseases have been done, but results were controversy ${ }^{12}$. A 20- year follow-up study of the original Whickham survey showed no association between elevated TSH and increased risk of IHD, while a report of 1149 women from Rotterdam showed increased atherosclerotic vascular disease and myocardial infarction in patients with subclinical hypothyroidism ${ }^{13}$. The present study showed that patient with subclinical hypothyroidism are at risk of developing Ischemic Heart Disease.

\section{Limitations}

There were several limitations to the study. We had a small sample size. This study could have been done as case-control study to have controls for comparison. We did not do Echocardiogram for those women who had symptoms of chest pain but standard Electrocardiogram were normal. Recall bias was another limitation of our study.

\section{Conclusion}

* Subclinical hypothyroidism is highly prevalent in elderly women above the age of 50 years $(31.25 \%)$. Most of those with subclinical hypothyroidism have the TSH level below $10 \mu \mathrm{IU} / \mathrm{ml}$.

* Patients with subclinical hypothyroidism are at risk of developing Ischemic Heart Disease.

\section{References}

1. Nystrom E, Bengtsson $\mathrm{C}$, Lindquist $\mathrm{O}$ et al: Thyroid disease and high concentration of serum thyrotropin in a population sample of women. Acta Med Scan, 1981; 210: 39-46.

2. Parle JV, Franklyn JA, Cross KW et al: Prevalence and follow-up of abnormal thyrotropin (TSH) concentration in the 
elderly in the United Kingdom. Clin Endocrinol, 1991; 34: 77-83

3. Vanderpump MPJ, Tunbridge WMG, French $\mathrm{M}$ et al: The incidence of thyroid disorder in the community: a twenty-year followup of the Whickham survey. Clin Endocrinol, 1995; 43: 55-68.

4. Althaus BU, Staub JJ, Ryff-De Leche A, Oberhansli A, Stahelin HB, 1988:LDL/HDL-changes in subclinical hypothyroidism: possible risk factors forcoronary heart disease. Clin Endocrinol (Oxf) 28:157-163.

5. Biondi B, Fazio S, Palmieri EA, Carella C, Panza N, Cittadini A, Bone F,Lombardi G, Sacca L, 1999: Left ventricular diastolic dysfunction in patients with subclinical hypothyroidism. J Clin Endocrinol Metab 84:2064-2067

6. Kahaly GJ, 2000: Cardiovascular and atherogenic aspects of subclinical hypothyroidism. Thyroid 10:665-679

7. Pucci E, Chiovato L, Pinchera A, 2000: Thyroid and lipid metabolism. Int J Obes Relat Metab Disord 24 (Suppl 2):S109S112

8. Danese D, Arduino G, Ardreoli M, Pontecorvi A: Screening for subclinical hypothyroidism in a flight personal population. Thyroid, 1997; 7: S-61

9. Tieche M, Lupi GA, Gutzweller F, Grob PJ, Studer H, Burgi H, 1981:Borderline low thyroid function and thyroid autoimmunity. Risk factors for coronary heart disease? Br Heart J 46:202-206

10. Ayala A, Danese MD, Ladenson PW: When to treat mild hypothyroidism. Endocrinol Metab Clin North Am, 2000; 29: 399-415

11. Lincolin SR, Ke RW, Kuttch WH: Screening for hypothyroidism in infertile women. J Reprod Med, 1999; 44: 455-57
12. Klein I, Ojamaa K. Thyroid hormone and the cardiovascular system. NEngl J Med 2001; 344:501-509

13. Hak AE, Pols HAP, Visser $\mathrm{T}$ et al: Subclinical hypothyroidism is an independent risk factor for atherosclerosis and myocardial infarction in elderly women: the Rotterdam study. Ann Intern Med, 2000; 132: 270-78. 